\title{
Modeling of GSM-Based Energy Recharge Scheme for Prepaid Meter
}

\author{
${ }^{1}$ B.O.Omijeh and ${ }^{2}$ G.I.Ighalo \\ ${ }^{I}$ Department of Electrical/Computer Engineering, Ambrose Ali University, Ekpoma, Edo State \\ ${ }^{2}$ Department of Electrical/Electronic Engineering,University of Port Harcourt, Port Harcourt, Rivers State
}

\begin{abstract}
This paper presents the design and modeling of a GSM-based Energy Recharge System for prepaid metering. It is observed that one of the faulty subsystems contributing to the huge revenue loss in Nigerian Power Sector is the metering and billing system. Errors get introduced at every stage of energy billing, like: errors with electro-mechanical meters, human errors while noting down the meter reading; and error while processing the paid bills and the due bills. The remedy for this drawback is a prepaid energy billing. There are clear results from many countries, where prepaid system has reduced the revenue loss by a large amount. This paper models a GSM-based Energy Recharge Interface which contains a prepaid card equivalent to a mobile SIM card. The prepaid card communicates with the power utility using GSM communication network. Once the prepaid card is out of balance, the consumer load is disconnected from the utility supply by the latching Relay (contactor). The power utility can recharge the prepaid card remotely through GSM/SMS mode base on customer requests. GSM-Based Recharge System(GBRS) for single phase prepaid meter has been modeled and simulated in Matlab/Simulink environment. The results obtained shows good system performance. A prior billing is bound to do away with the problems of unpaid bills and human error in meter readings, thereby ensuring justified revenue for the utility.
\end{abstract}

Keywords: GSM, Energy meter, Microcontroller, Prepaid card, Recharge

\section{Introduction}

Recent trends in digital technologies have resulted to monumental developments in wireless communications which clearly shows that the place of Global System for Mobile Communications (GSM) technology cannot be over-emphasized. This paper therefore, explores its possibilities in the implementation of a GSM-Based Recharge Scheme for Energy Prepaid Meter (Omijeh, 2012). What is new in the overall design is the GSM-Based Recharge Module (GBRM) which consist primarily of a Microcontroller and a GSM communication module with a prepaid card (specially programmed SIM) along with a latching Relay and a liquid crystal display (LCD).

\subsection{Related works}

Shwehdi and Jackson (1996) in their paper, presented the Digital Tele-wattmeter System as an example of a microcontroller- based meter. The meter was implemented to transmit data on a monthly basis to a remote central office through dedicated telephone line and a pair of modems. It is only a stand-alone metering system. Zhang, Oghanna and Bai (1998) utilized a DSP-based meter to measure the electricity consumption of multiple users in a residential area. A Personal Computer (PC) at the control centre was used to send commands to a remote meter, which in turn transmitted data back, using the power Line Communication (PLC) technique. The major problem with this system is that it cannot detect tampering by consumers.

Koay, Cheah, Sng, Chong, Shun and Tong (2003) in their work, designed and implemented a Bluetooth energy meter where several meters are in close proximity, communicated wirelessly with a Master PC. Distance coverage is a major set-back for this kind of system because the Bluetooth technology works effectively at close range.

In their paper, Scaradozzi and Conte (2003) viewed home- automation systems as Multiple Agent Systems (MAS). Home automation system was proposed where by home appliances and devices are controlled and maintained for home management. It is only a home management system and does not measure the amount of energy consumed by users.

Hong and Ning (2005) in their paper, proposed the use of Automatic Meter Reading (AMR) using wireless networks. Some commercial AMR products use the internet for data transmission.

Stanescu, D, Ciubotaru-Petrescu, Chiciudean, and Cioarga (2006) present a design and implementation of SMS -based control for monitoring systems. The paper has three modules involving sensing unit for monitoring the complex applications. The SMS is used for status reporting such as power failure. Issues on billing system for electricity board usage were not considered. 
Prepaid meters can also make use of state of art technologies like WiMAX owing to the idea of centralized accounting, monitoring and charging. It brings telecommunication to the core of its activities to support more Smart Grid applications such as Demand Response and Plug-in electric vehicles (Khan et al, 2007). Prepayment polyphase electricity metering systems have also been developed consisting of local prepayment and a card reader based energy meter (Ling et al, 2010).

Malik, Aihab and Erum (2009) in their paper, mainly focused on the controlling of home appliances remotely and providing security when the user is away from the place using an SMS- based wireless Home Appliance Control.

In their paper, Maheswari and Sivakumar (2009) aimed to develop an energy efficient and low cost solution for street lighting system using Global System for Mobile communication [GSM] and General Packet Radio Service [GPRS]. The whole set-up provides the remote operator to turn off the lights when not required, regulate the voltage supplied to the streetlights and prepare daily reports on glowing hours

Sharma and Shoeb (2011), in their paper suggested a method where we utilize telecommunication systems for automated transmission of data to facilitate bill generation at the server end and also to the customer via SMS, Email.

Amit. J and Mohnish (2011). Suggested in their paper, a prepaid energy meter behaving like a prepaid mobile phone. The meter contains a prepaid card analogous to mobile SIM card. The prepaid card communicates with the power utility using mobile communication infrastructure. Once the prepaid card is out of balance, the consumer load is disconnected from the utility supply by the contactor. The power utility can recharge the prepaid card remotely through mobile communication based on customer requests.

\section{2 Reliability of GSM Short Messaging}

Global System for Mobile Communications (GSM) is the world's most popular standard for mobile telephony systems .GSM is used by over 1.5 billion people across more than 212 countries and territories. GSM also pioneered low-cost implementation of the short message service (SMS) which allows parties to exchange delay tolerant short text messages. The popularity and wide coverage of cellular networks have attracted researchers to consider the use of SMS service. However there are certain questionable issues regarding GSM network such as its scalability, reliability and security, especially under high load. Zerfos et al (2006) have analyzed real data taken from a real GSM network in India. SMS delivery success rate was found to be $94.9 \%$; $73.2 \%$ of the successfully delivered messages reach to the destination within 10 seconds; about $5 \%$ of them require more than an hour and a half. Using SMS for AMR service will definitely increase the flow of messages tremendously. GSM uses several cryptographic algorithms for security. The development of UMTS introduces an optional Universal Subscriber Identity Module (USIM), which uses a longer authentication key to give greater security, as well as mutually authenticating the network and the user.

\section{GSM-Based Recharge Billing System Architecture}

The block Diagram of the GSM-Based Recharge Billing System is shown in Fig.1. It consist of three main parts, namely: The Digital Energy Meter, the GSM-Based Recharge Module and the Public Utility Control Center (PUCC) server.

2.1 Digital Energy Meter: It contains a Metering IC which measures the current and voltage signals and generates instantaneous active power. The instantaneous active power values are continuously integrated to an active energy register, the value of which is periodically accessed by the microcontroller via SPI (Serial Peripheral Interface). The microcontroller uses the retrieved active register value to calculate the active power consumed. A real time clock is also implemented on the microcontroller, which enables timestamps to be generated, so the synchronization between the PUCC server and the meter can be established. 


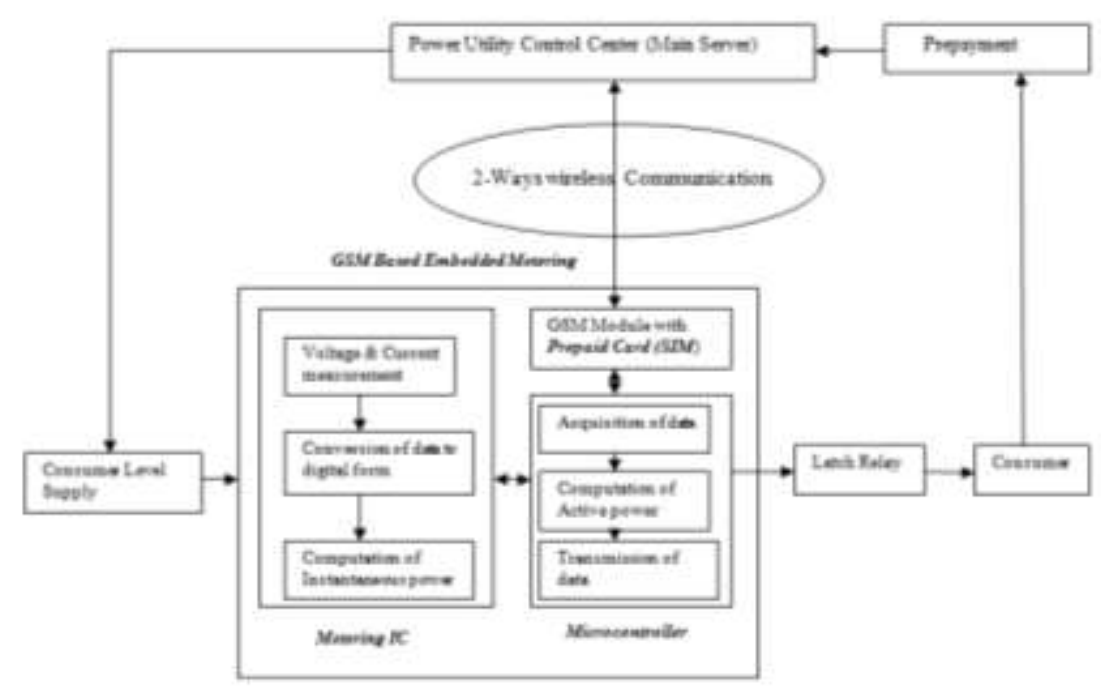

Fig 1: GSM-Based Recharge Billing System Architecture

2.2. Microcontroller: The microcontroller is programmed to read data from the metering IC every second. The active meter of the metering IC is not reset after it has been accessed, thus when the microcontroller reads the data from the active register, this value is stored and then subtracted from the next reading to determine the actual instantaneous power value. The difference between the current and previous values is called the delta value. The active register of the metering IC also wraps around every 52 seconds and this is rectified in software.For each reading the new delta value is added to the previous delta values the accumulated is compared to a threshold value. The threshold value is the amount of energy measured by the meter before a pulse is generated.The threshold value is calculated by dividing the energy represented by a light emitting diode (LED) pulse by the energy per register count i.e

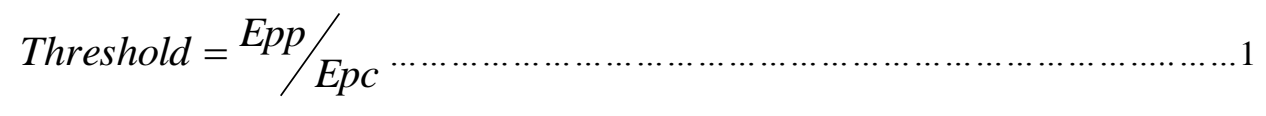

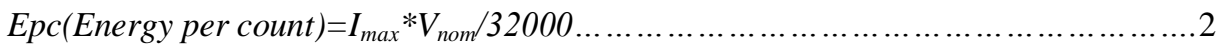

Where Epp is the energy per pulse, Epc is the energy per count, $I_{\max }$ is the maximum load and $V_{\text {nom }}$ is the norminal voltage.

The active register increments at 32000 samples per second, therefore a single count of the energy corresponds to an amount of energy expressed in Ws(Watt seconds). The pulse rate required for the meter is usually expressed in pulses/kWh. A single pulse on an LED is a fraction of a $\mathrm{kWh}$ and is converted to energy in Ws/pulse i.e

Epp $($ Energy per LED pulse $)=1000 * 3600 / \mathrm{Mpr}$ 3

Where Mpr is the pulse rate of the meter in pulses/kWh. The formulas used in this section were based on information obtain from (SAMES, " Single Phase Power/Energy IC with SPI". Available:http://www.sames.co.za,pp.1-12, undated.

\subsection{Latching Relay}

A Latching Relay is the connecting link between the consumer load and utility supply. The opening and closing of this latching relay depends on the balance present in the prepaid card at a moment. While the prepaid card has some some amount more than zero, it stays closed and keeps the utility supply uninterrupted to the consumer load. When the card runs out of balance, it opens and disconnects the load from the supply. Hence, even when the energy meter receives voltage supply, it does not reach the load while the latching relay is open because the balance in the prepaid card is not available. Since the latching Relay too will consume some amount of electrical energy, it is inclusive in the calculations made by meter and prepaid card. 
2.4 GSM-Based Recharge System: The power utility sets the amount in the prepaid card to a measure that the consumer recharges the card to, called Recharged Amount $\left(R_{A}\right)$. The tariff rates are already programmed and fed into the card. As the load is consumed, the meter sends the units consumed to the prepaid card which continuously converts these units into Expenditure (E) at each instant and then subtracts it from the Recharged Amount to obtain a Balance (B).

Mathematical Model

$R_{A}-E=B$ 4

In Nigerian billing structure (Nwaoko,2006)., Expenditure is given by the expression below:

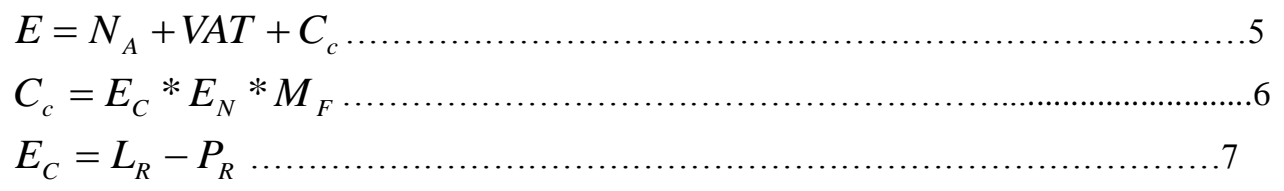

Where $\mathrm{N}_{\mathrm{A}}=$ Net Arrears; VAT $=$ Tax; $\mathrm{C}_{\mathrm{C}}=$ Current Charge; $\mathrm{E}_{\mathrm{C}}=$ Energy Consumed; $\mathrm{L}_{\mathrm{R}}=$ Last Reading; $\mathrm{P}_{\mathrm{R}}=$ Present Reading; EN= Energy Charge per KWh; $\mathrm{M}_{\mathrm{F}}=$ Multiplier Factor.

From equation 5, when the Expenditure $(\mathrm{E})=$ the Recharged Amount $\left(\mathrm{R}_{\mathrm{A}}\right)$, the Balance $(\mathrm{B})$ becomes zero. Then the microcontroller triggers the Latching Relay to open and the consumer is disconnected. This action is reversed when the consumer recharges again.

\subsection{Power Utility Control Center-Recharging Process}

The process of purchase and recharge is explained thus, the power utility produces scratch-cards and distribute them to local shops. Customers buy scratch-cards from their nearby shop and then send a special SMS using their personal cellular phone to the central server consisting of the customer's meter ID and the scratchcard's secret pin number. When the central server receives the SMS, it checks the validity of the meter ID and the pin number from the database. If the meter ID is valid and the pin number is also valid and still unused, then the server gets the customer meter's GSM modem call number from the database and sends an encrypted SMS to the customer's meter which contains the information of how much balance will be recharged in the meter. The meter receives the SMS, decode it and recharge the balance. Then it sends an acknowledgement SMS to the server indicating whether the balance is successfully recharged or not. After receiving the acknowledgement from the meter, the server then sends a report SMS to the customer's personal cellular phone mentioning the meter's current balance. The prepaid card sends a signal to the contactor for monitoring the supply to the consumer.

\section{Modeling of Energy Billing System in Matlab/Simulink Environment}

Figure 2 below represents the energy billing meter model consisting of three subsystems:

a. The utility company model that simulates the energy utility company providing the necessary energy for utility consumption

b. The Energy billing meter model that simulates consumer energy metering

c. The Recharge model that simulates the recharge mode used by the energy consumer.

The energy billing algorithm is fully implemented by the interpreted MATLAB Fcn block which accepts a multiplex set of input measurements and outputs the energy balance left for the consumer. See Figure 3. 

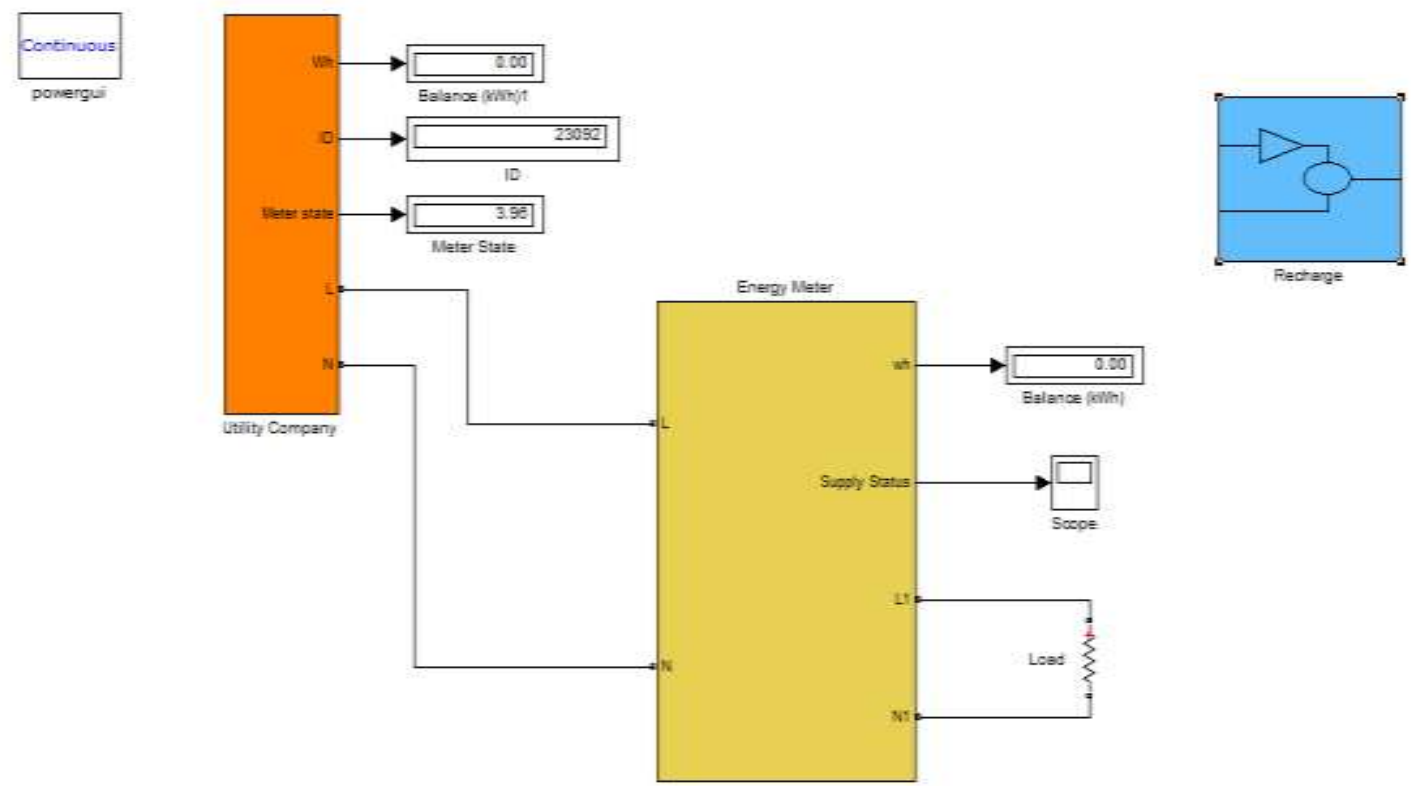

Fig 2: Energy metering and billing system models

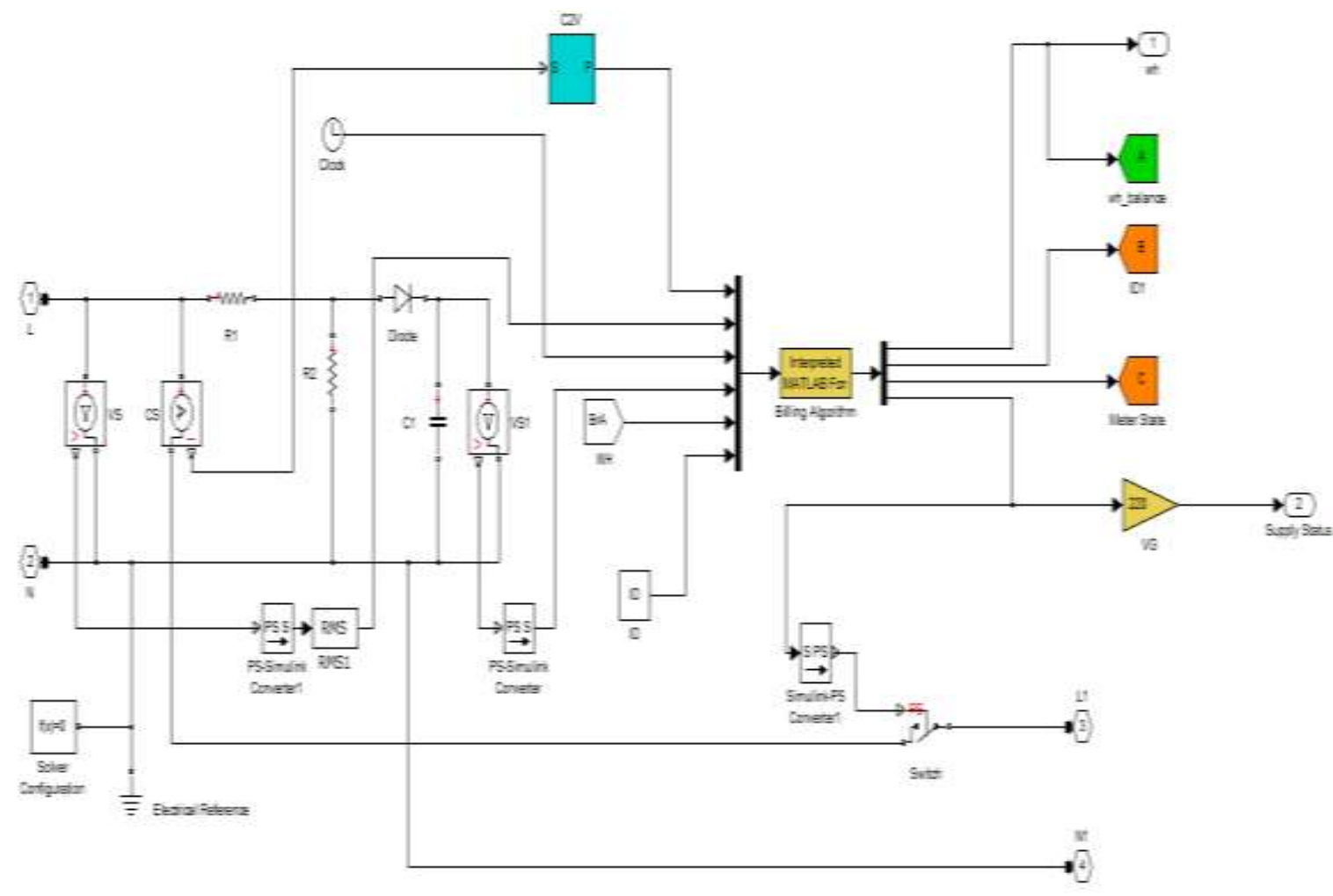

Figure 3: Internal implementation of Energy Meter block

The Energy Billing algorithm

- Read the rms values of the load voltage, current drawn, simulation time, internal meter voltage, Purchased Watt-Hour and meter ID. These are all multiplexed and supplied as input to the interpreted MATLAB function block.

- Calculate Consumed active watt-hour rate (Wh)

- Subtract Consumed active watt-hour rate from Purchased Watt-Hour to get energy balance

- Close contactor if balance is available or open it otherwise 
IV. Results and Discussion
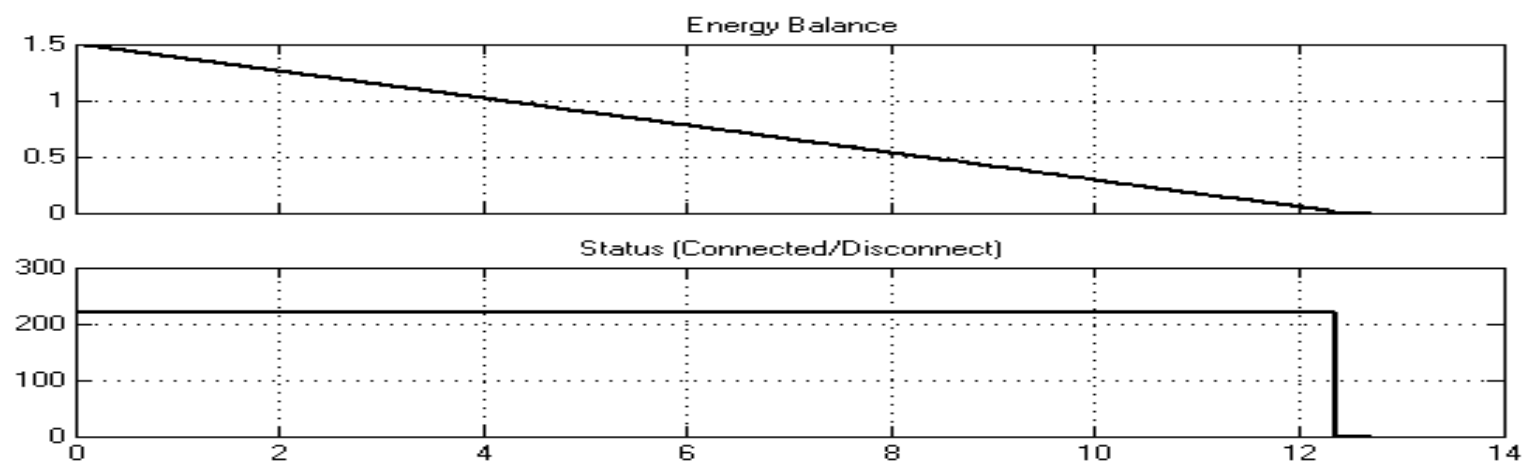

ime offset: 0

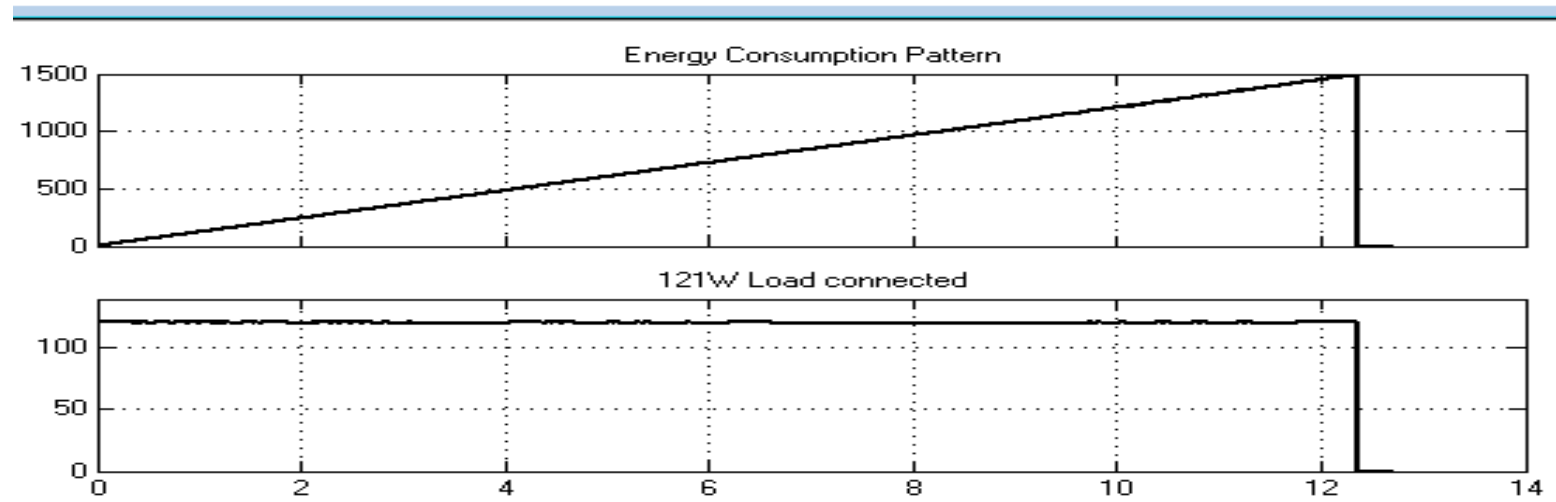

ime offset: o

Fig.4: $1500 \mathrm{~W}$ Prepaid Billing for $121 \mathrm{~W}$ Load
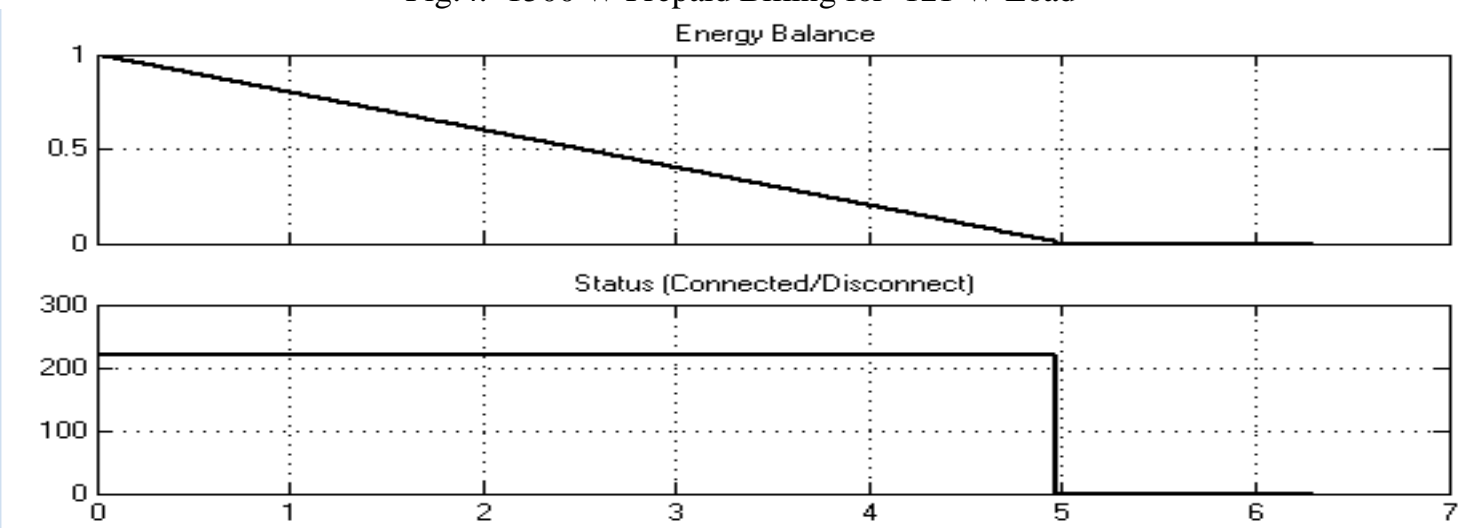

Time offset: 0

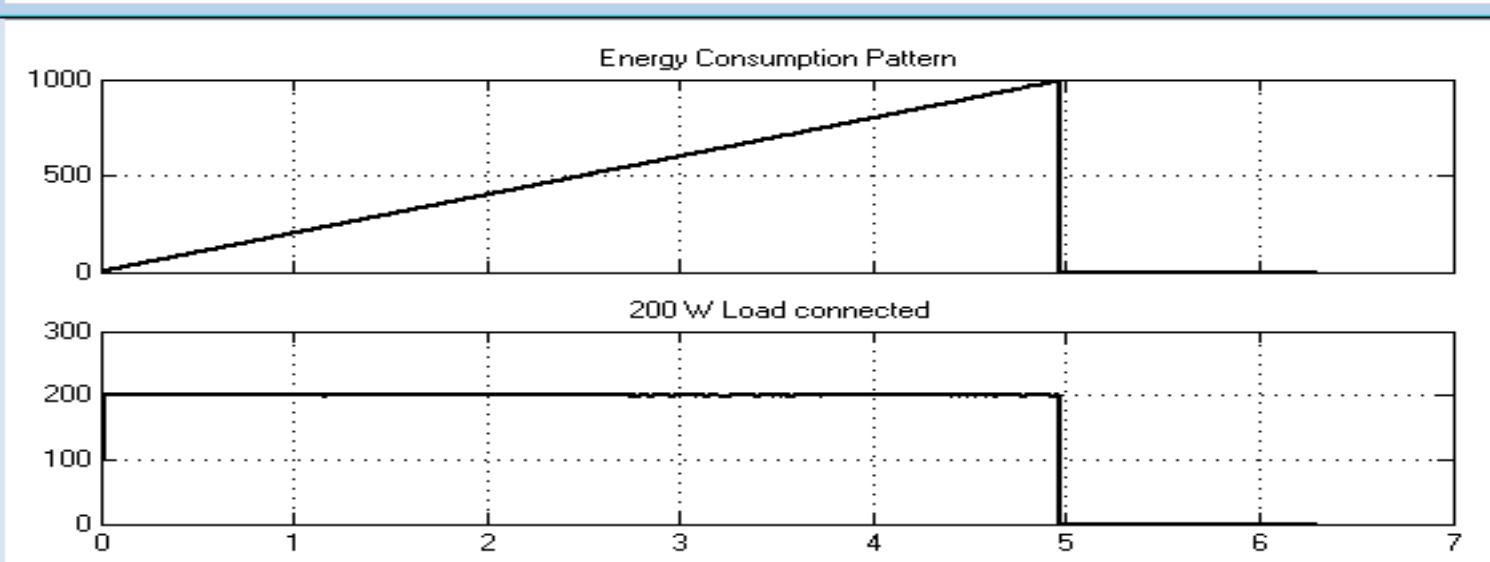

Fig.5: 1000W PREPAID BILLING FOR $200 \mathrm{~W}$ LOAD CONNECTED. 


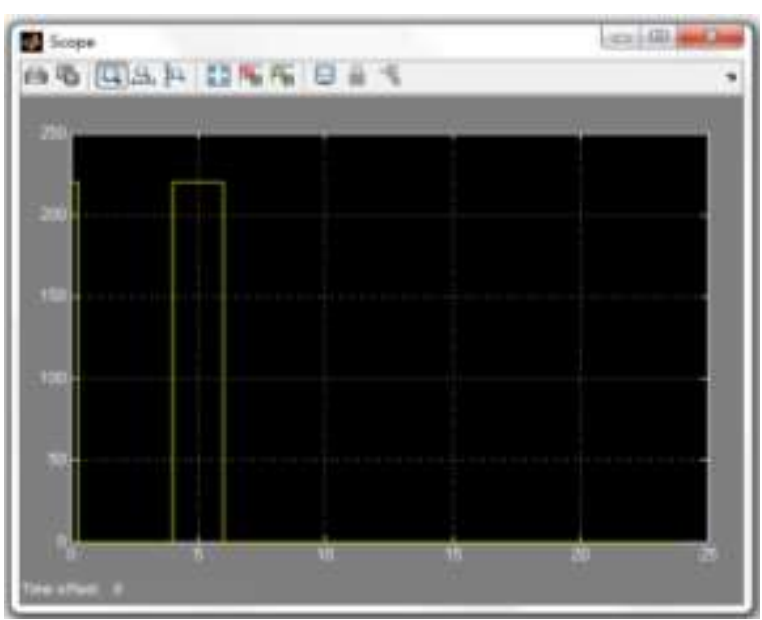

Fig.6: Electrical Output Status based on consumer recharge for load of $484 \mathrm{~W}$

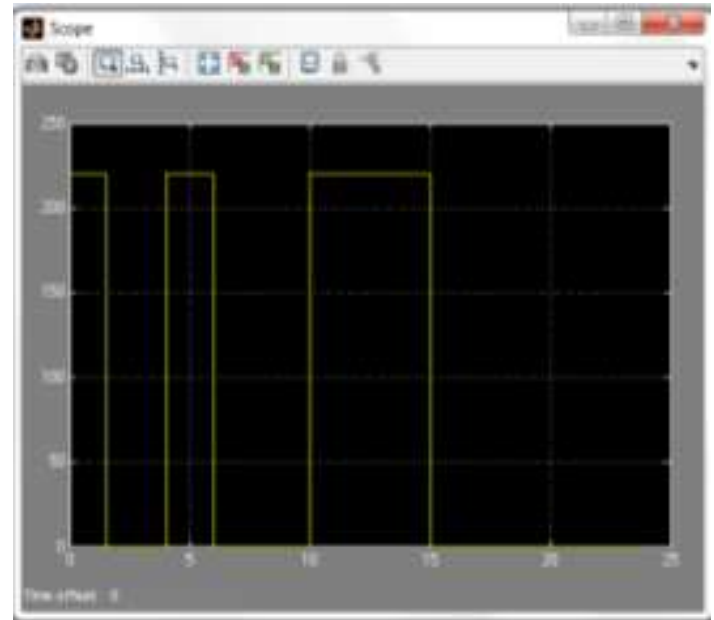

Fig.7: Electrical Output Status based on consumer recharge for load of $60.5 \mathrm{~W}$

\section{Discussion}

I. From Fig.4, Graph 1, the maximum energy level observed is1.5KW on the y-axis. This represents the amount of Energy purchased. This satisfies the equation;

$$
\mathrm{E}_{\mathrm{B}}=\mathrm{E}_{\mathrm{R}}-\mathrm{E}_{\mathrm{C}} \text {. }
$$

At $\mathrm{t}=0, \mathrm{E}_{\mathrm{C}}=0, \mathrm{E}_{\mathrm{B}}=\mathrm{E}_{\mathrm{R}}$

$E_{R}=$ Energy Recharged, $E_{C}=$ Energy Consumed, $E_{B}=$ Energy balance, $t=$ simulation time.

II. From Fig.4, Graph 1, it was observed that from the count of energy consumption by the consumer, the value of the energy balance decreased gradually until it got to zero. This also satisfies the equation:

$$
* \mathrm{E}_{\mathrm{B}}=\mathrm{E}_{\mathrm{R}}-\mathrm{E}_{\mathrm{C}}
$$

III. From Fig 4, the energy balance pattern in Graph 1is observed to be the reverse of energy consumption pattern in Graph 2.

IV. From Fig 4, Graphs 1and 3,it is observed that, the energy balance pattern has a negative slope (gradient) while that of the energy consumption pattern is positive.

V. In Fig 4, Graph 2, The consumers remained connected at 220 volts until energy balance was exhausted (zero). This shows the effectiveness and efficiency of the IPEBS. Whenever the energy balance in the meter is exhausted the consumer is disconnected automatically. Which shows good energy accountability between the consumer and the utility company.

VI. From Fig 4, in Graph 4, it is observed that the rated load connected is $121 \mathrm{~W}$.

VII. A very important observation is made in Fig 4. The four different graphs terminated at the same time showing the accuracy of the IPEBS model. This means that the energy consumption of the user is regulated by how much Energy Recharge Units (ERU) purchased. This also reflects transparency and integrity of Energy metering and billing transactions.

VIII. In Fig 5, the Energy consumption termination time is shorter than that in Fig 4. This is due to two reasons: (i) the $161 \mathrm{~W}$ load connected in Fig 5 is greater than the $121 \mathrm{~W}$ load connected in Fig 4 .(ii) The rate of energy consumption is dependent on the rated Load.

IX. Fig.6 and Fig.7 show that different loads with the same recharge have different electrical outputs.

\section{Conclusion}

In this paper, GSM-Based Energy Recharge Scheme for Nigerian Power Utility Company has been modeled. The entire system can be cost effective and significant amounts of time and money can be saved by implementing it, as opposed to one involving the human element. Human errors in billing would be totally eliminated and a more convenient way of purchasing energy credits and recharging Energy Meter. It's reliable as consumers are only allowed to use what they pay for thereby reducing revenue loss due to unpaid bills. If fully implemented by Nigerian Power Sector, revenue collection will increase. 


\section{Reference:}

[1] Amit. J and Mohnish (2011). B- A Prepaid Meter using mobile communication International Journal of Engineering, Science and Technology-Vol. 3, No. 3, 2011, pp. 160- 166

[2] Hong. L and Ning.L (2004). Design and Implementation of Remote Intelligent Management System for City Energy Resources base on Wireless Network. Study of Computer Application 12:237-239.

[3] Jawarkar, N. P, Ahmed, V, Ladhake, S. A and Thakare, R. D (2008). Micro-controller based Remote Monitoring using Mobile through Spoken Commands. Journal of Networks 3:58-63.

[4] Koay .B.S, Cheah.S.S, Sng .Y.H,Chong. P.H.J, Shun.P,Tong.Y.C (2003) . Design and implementation of a Blue tooth energy meter. proceedings of the Joint $4^{\text {th }}$ International Conference on Information, Communication and Signal Processing and the $4^{\text {th }}$ Pacific Rim Conference on Multimedia .3: 1474-1477

[5] Maheswari, C; Jejanthi, R (2009). Implementation of Energy Management Structure for street Lighting System. A Journal of Modern Applied Science 5:6-10.

[6] Malik S.H .1, Aihab. K, and Erum .S (2009). SMS Based Wireless Home Appliance Control System (HACS) for Automating Appliances and Security. Issue in informing Science and Information Technology 6:887-894.

[7] Nair, L.R and Maharaj, B.T(2004)-Efficient Digital GSM/GPRS Metering for Rural Electrification.

[8] http://www.ursi.org/Proceedings/ProcGA05/pdf/C01.5\%2801208\%29.accessed 2010.

[9] Nwaoko kosi JOY (2006). Electrical Energy Accounting Methods. Impressed Publishers, Lagos Nigeria, 1-8.

[10] Omijeh.B.O- "Ph.D Thesis on the Design and Evaluation of GSM-based Intelligent Prepaid Energy Metering System for Nigeria" Ambrose Alli University, Ekpoma, 2012.

[11] Scaradozzi, D and Conte, G. (2003). Viewing home automat ion systems as multiple agents systems. RoboCUP2003,Padova,Italy.Retrievedfrom http://www.robosiri.it/ROBOCUP_2003/ROBOCUPSITOSIRI/articles/pdf/Conte.pdf

[12] Schwendtner.M.F (1996). Technological developments in electricity metering and associated. proceedings of the $8^{\text {th }}$ International Conference on Metering and Tarriffs for Energy Supply 8:240-242.

[13] Sharma.S and Shoeb.S. (2011)- Design and Implementation of wireless automatic meterreading system . International Journal of Engineering Science and Technology (IJEST)- Vol. 3, No. 3,March 2011, pp. 2329-2334.

[14] Shwehdi.M.H and Jackson.C (1996). A microprocessor based digital wattmeter system design. proceedings of the $31^{\text {st }}$ Intersociety Conference on Energy Conversion Engineering 31:1840-1845.

[15] Stanescu, D, Ciubotaru-Petrescu, B., Chiciudean, D., Cioarga, R.. (2006). Wireless Solutions for Telemetry in Civil Equipment and Infrastructure Monitoring. 3rd Romanian-Hungarian Joint Symposium on Applied Computational Intelligence (SACI) . Retrieved from http://www.bmf.hu/conferences/saci2006/Ciubotaru.pdf

[16] Wasi-ur-Rahman.M, Tanvir.A, and Lutful K.(2009)- Design-of-an-intelligent-SMS-based-remote-metering-system. International Conference on Information and Automation 2009.ICIA'09, pp: 1040-1043

[17] Zhang.J, Oghanna and Bai.C.L (1998). DSP based electricity meter with remote reading. proceedings of the $4^{\text {th }}$ International Conference on Signal Processing $2: 1581-1584$

[18] Zerfos.P, Meng.K, Wong.S, Samanta.V, and Lu.S “A study of the short message service of a nationwide cellular network," in ACM SIGCOMM Internet Measurement Conf., Oct. 2006

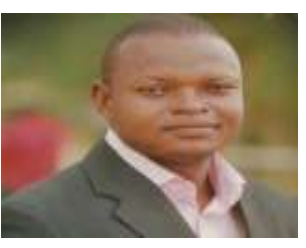

\section{Author's biography}

Bourdillon .O. Omijeh holds a B.Eng Degree in Electrical/Electronic Engineering and M.Eng.Degree in Electronics/Telecommunications Engineering from Ambrose Alli University (A.A.U), Ekpoma and University of Port Harcourt respectively. His research areas include: Artificial Intelligence, Robotics, Embedded Systems Design, Modeling and Simulation of Dynamic systems, Intelligent Metering Systems, Automated Controls, Telecommunication and ICT. He is currently a Lecturer in the department of Electrical/Electronic Engineering, University of Port Harcourt, Rivers State, Nigeria. He is a corporate member of Nigerian Society of Engineers (NSE), Council for the Regulation of Engineering in Nigeria (COREN) ;and also, a registered Consultant to

Companies and Institutions.

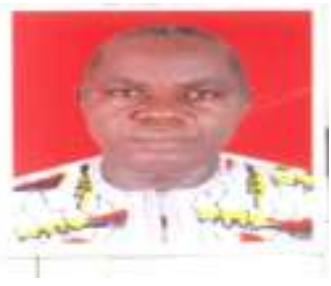

Godwin.I. Ighalo is an associate Professor/ Consultant in the Department of Electrical/Electronic Engineering, Ambrose Alli University, Ekpoma, Edo State, Nigeria . He holds a B. Eng, M. Eng, and a $\mathrm{PhD}$ in Electrical/Electronic Engineering. He has published over twenty five (25) research papers in both national and international peer reviewed journals. His research interest includes: Electronics, Telecommunication, ICT and Computer Engineering. He is a corporate member of Nigerian Society of Engineers (NSE), Council for the Regulation of Engineering in Nigeria (COREN) . 